\title{
Implementation of an ecosystem model for assessment of management policy based on sustainability criteria
}

\author{
Yael Gilboa $^{\text {a }}, \underline{\text { Gideon Gal }}^{\text {b }}$, Arkadi Parparov ${ }^{\text {b }}$ and Eran Friedler ${ }^{\text {a }}$ \\ a. Faculty of Civil and Environmental Engineering, Technion - Israel Institute of Technology, Haifa \\ 32000, Israel \\ b. Y. Allon Kinneret Limnological Laboratory, Israel Oceanographic \& Limnological Research, P.O. \\ Box 447, Migdal 14950, Israel \\ Email: gal@,ocean.org.il
}

\begin{abstract}
We implemented the 1-D lake ecosystem model DYRESM-CAEDYM (DYCD) to the subtropical meso-eutrophic Lake Kinneret, in order to determine an acceptable management policy based on sustainability criteria. The sustainability criteria were defined based on the Lake Kinneret system of water quality indices (WQI) and composite water quality index (CWQI) developed for the lake. The CWQI was evaluated by number of parameters that are monitored routinely at the lake and provide an overall picture of many of the ecosystem processes.

Both the WQI and CWQI were applied in conjunction with output from $10 \mathrm{yr}$ model scenarios, which included a wide range of nutrient loads and lake levels. In both cases, the scenarios covered a range wider than that historically observed in the lake. The scenarios included both simple cases of changes to one of the management forcing variables (e.g. lake level) and more complex cases that modified multiple forcing variables in tandem. We used the hydroecological model DYCD and ran it at WLs ranging between -209 to $-218 \mathrm{~m}$ under varying nutrient loads, 0.56 to $56.6 \mathrm{gNm}^{-2} \mathrm{y}^{-1}$ and 0.039 to 3.9 $\mathrm{gPm}^{2} \mathrm{y}^{-1}$.

For levels ranging between -209 to $-213.4 \mathrm{~m}$ simulation results allowed us to assess the direct relationships between nutrient loads and CWQI. The graphical solution of these relationships represents a "polygon" of permissible ranges and critical values of nutrient loads allowing conservation of the lake WQ at each WL. We used the combination of the model scenario results and the quantified WQ output to define a 3D (TN, TP and water level) space of acceptable management measures. The space defines the magnitude of management measures that can be performed on the lake ecosystem while sustaining the ecosystem.

The results suggest a wider than expected range of management measures that can be used in the lake ecosystem, but the reaction of the ecosystem to the measures is not linear. As a result, reducing management measures does not always lead to improved sustainability.

This approach is unique, and the first example of implementation of a management tool that integrates nutrient loads and WL through a WQ system. This approach could be implemented in other lakes around the world that suffer from deterioration in water quality as a result of changes in water level and nutrients loads.

The application of a process based model, such as DYCD, has provided a means for examining the impact of external forcing on the lake ecosystem, beyond the observed historical conditions, and over extended periods of time. Our study demonstrates the major advantage associated with the use of process based ecosystem models as a tool for research and management.
\end{abstract}

Keywords: sustainability criteria, water quality, water level, WQI, CWQI, nutrient load permissible range 


\section{INTRODUCTION}

Water quality (WQ) in lakes and reservoirs is of major concern worldwide (Wang 2001). As water is more intensively used and as WQ deteriorates, there is an increasing need for improved decisionmaking processes to manage water quality and quantity, from both an ecological and economic point of view (Priazhinskaya, 2002; DeJong et al., 1996). The need for management of water resources reflects an understanding that these resources are not infinite and have limited stability under anthropogenic forcing (Gal et al., 2009). In order for resources management to be successful, a sound scientific basis and a clear understanding of ecosystem processes are necessary.

It has been recognized that the quality of receiving waters is affected by human activities in the watershed, such as the appearance of various point and non-point sources of agricultural, industrial, and sewage pollutants, especially nutrients and sediment loading (Berman, 1998; Wang 2001). Lake management impacts lake water quality via water supply due to different pumping regimes from the lake. Different regimes of water supply can result in large changes in the morphometric parameters of the lake (e.g. the ratio of the epilimnion depth to the hypolimnion thickness) caused by drastic changes to the lake water level. These changes are considered a management factor as important as nutrient loading (Folke at el. 2004). Therefore, nutrient loads and water level beyond critical values may lead to significant deterioration of water quality. Sustainable management requires establishment of the relationships between WQ and management factors such as nutrient loading and pumping of water from the lake (Gal et al., 2009). Hambright et al. (2000) developed a system of water quality indices (WQI) based on various chemical, physical and biological parameters that are monitored routinely in Lake Kinneret, Israel. In this WQI system, WQ, which is mainly impacted by human activities, is expressed by metrics that allow analytical expression of relationships between WQ and various management factors, and in relation to a reference state (Hambright et al. 2000). As the acceptable ranges of the WQI were determined to ensure lake conditions similar to those found during the reference period, the WQI system's measurable parameters express sustainability criteria for the lake. Hence through the use of the composite water quality index (CWQI, Parparov and Hambright, 2007) required management actions for lake sustainability can be determined. In this paper, we demonstrate the acceptable management policy by studying the combined effect of nutrient loads and water levels on WQ that allows sustainability of the ecosystem in question. We tested this approach on the Lake Kinneret ecosystem and defined the range of acceptable management measures through the use of long term simulations of different scenarios.

\section{MATERIALS AND METHODS}

\subsection{Lake Kinneret}

Lake Kinneret is a warm-monomictic lake located at about $-210 \mathrm{~m}$ altitude (i.e. below mean sea level) in the northern part of the Dead Sea Rift Valley (part of the Afro-Syrian Rift Series). The limnology of the lake is well documented (Serruya, 1978). The lake is $22 \mathrm{~km}$ long and $12 \mathrm{~km}$ at maximum width; maximum and mean depths are 44 and $24 \mathrm{~m}$, respectively, and the surface area is $170 \mathrm{~km}^{2}$. Lake Kinneret is meso-eutrophic with a mean annual primary production of $650 \mathrm{gCm}^{-2}$ (Berman et al., 1995). Since the mid-1990's the lake ecosystem has, however, undergone a number of significant changes that are most likely linked to lake, or watershed, management (Zohary 2004, Gal and Williamson 2010, Zohary and Ostrovsky 2011) Further details on the basic ecology of the lake, prior to the changes, can be found in Berman et al. (1995).

\subsection{Models description:}

\subsubsection{Water Quality approach:}

Our determination of the acceptable management policy for Lake Kinneret, was based on sustainability criteria represented by the water quality indices (WQI) and composite water quality index (CWQI) developed for the lake. Eleven parameters that are monitored routinely at the lake were chosen to be those by which water quality will be evaluated (Table 1, Hambright et al., 2000). The parameters selected for the WQI provide an overall picture of many of the ecosystem processes. The WQI system was designed around a basic understanding that proper management of Lake Kinneret implies preserving an ecosystem that conforms to a predefined reference state, corresponding to conditions when all major uses were satisfied. The reference state was defined as the condition of the lake during the period 1969 - 1991 (Hambright et al., 2000). The ecosystem values (e.g. concentrations) of the WQI were related to numeric rating values by standardizing water quality parameters to a $0-100$ scale 
$(0<\mathrm{R}<100)$ so rating curves could be established, which were than presented as analytical expressions (Parparov et al., 2006). Acceptable ranges for the separate water quality indices were restricted to the range 60-100. The water quality indices were aggregated into a Composite Water Quality Index, which is a weighted sum of the individual parameters ratings (CWQI; Parparov and Hambright, 2007).

As the underlying assumption governing the WQI values was sustaining the lake ecosystem, there is a set of management measures (MM) that maintain the aggregated WQ (CWQI) within its permissible range $(60 \leq \mathrm{CWQI} \leq 100)$, eq. 1 . These limits (eq. 1), and the MM that permit activity in the ecosystem within these limits in essence define the sustainable management policy of the water resource in question.

$$
\{\mathrm{MM}\} \leftrightarrow 60 \leq \mathrm{CWQI} \leq 100
$$

A methodological approach to, and a first outline of, the sustainable management policy for Lake Kinneret was developed by Parparov \& Gal (submitted).

\subsubsection{DYCD model:}

For estimating the ecosystem values of the WQI for different scenarios we used the hydroecological suite of models DYRESM-CAEDYM (DYCD; Hipsey et al., 2006, Bruce et al. 2006). DYCD consists of the Computational Aquatic Ecosystem Dynamics Model (CAEDYM) coupled to the onedimensional physical model: DYnamic REServoir Model (DYRESM). The ecological model, CAEDYM, explicitly models the inorganic, organic, phytoplankton and zooplankton components of carbon, nitrogen and phosphorus; the model includes process representation of the C, N, P, Si cycles and dissolved oxygen. CAEDYM is more advanced than traditional nutrients-phytoplanktonzooplankton models, as it is a general biogeochemical model that can resolve species- or group-specific ecological interactions. The model contains seven groups of phytoplankton and five groups of zooplankton. Five groups of phytoplankton and three groups of zooplankton are used in the Lake Kinneret application of the model. This ecological configuration was considered to resolve most of the observed seasonal biogeochemical variability (Gal et al. 2009). DYRESM is a one-dimensional hydrodynamic model for predicting the vertical distribution of temperature, salinity and density in lakes and reservoirs (Imberger and Patterson 1981). In DYRESM, the lake is represented as a series of homogeneous horizontal Lagrangian layers of variable thickness. The main processes modeled in DYRESM are surface heat, mass and momentum transfers, mixed layer dynamics, hypolimnetic mixing, benthic boundary layer mixing, inflows and outflows. Local meteorological data are used to determine penetrative heating due to short-wave radiation and surface heat fluxes due to evaporation, sensible heat, long-wave radiation and wind stress. Both DYRESM (Gal et al 2003) and DYCD (Bruce et al 2006, Gal et al. 2009, Makler-Pick et al., 2011) have been applied in the past to Lake Kinneret.

\subsection{Management scenarios:}

In order to assess the relationships between the selected management measures (nutrient loads and water level) and lake water quality, we conducted a series of 10-year simulations, using DYCD. The 10-year simulations input data were constructed based on long-term monitoring data collected at the Kinneret Limnological Laboratory. The base simulation was based on perennial mean data and was replicated 10 times in order to achieve model pseudo-stability by reducing any inter-annual variability in the forcing data. For each of the scenarios we balanced withdrawal volumes so lake levels varied only seasonally and not inter-annually over the course of the simulations. The level of nutrient loading into the lake was varied over a wide range of loadings by multiplying the concentration of $\mathrm{N}, \mathrm{P}$ or $\mathrm{N}$ and $\mathrm{P}$ in tandem ( $\mathrm{N}$ load, $\mathrm{P}$ load and $\mathrm{N} \& \mathrm{P}$ scenarios, respectively) in the inflows. 
The multiplication factors used were $\mathrm{x} 0.1, \mathrm{x} 0.2, \mathrm{x} 0.5, \mathrm{x} 1, \mathrm{x} 2, \mathrm{x} 5$, and $\mathrm{x} 10$ where $\mathrm{x} 1$ represents the base line. Mean annual $\mathrm{N}$ and $\mathrm{P}$ loading at the $\mathrm{x} 1$ level were $5.66 \mathrm{gNm}^{-2} \mathrm{y}^{-1}$ and $0.39 \mathrm{gPm}^{-2} \mathrm{y}^{-1}$, respectively. When changes were made to only $\mathrm{N}$ or only to $\mathrm{P}$ concentrations, a by-product was a change to the N:P ratio of the incoming nutrients. Under the N\&P loading scenarios, the N:P ratio was maintained at all levels of multiplication while concentrations, and hence loading, changed. It must be noted that the ranges of loads we examined, in the scenarios, exceeded historical ranges. This was done in order to test broader management measures than those practiced in the past. The scenarios were examined over a wide range of water levels (WL) varying between -209.0 and $-218.0 \mathrm{~m} \mathrm{BSL}$ (below sea level) at a $1 \mathrm{~m}$ resolution. For each simulation the WQIs and CWQI were calculated, which were then pooled so that the acceptable ranges for each management measure ( $\mathrm{N}$ load, $\mathrm{P}$ load, WL) were defined separately and combined (fig 1). Examination of the scenario results were based only on means of the last 3 years of the simulations in order to avoid any instability occurring during the first few years of the simulations. For the last 3 years, the mean monthly values for the upper $10 \mathrm{~m}$ of the water column were computed. The averages of all 3 years were then used to compute mean annual values.

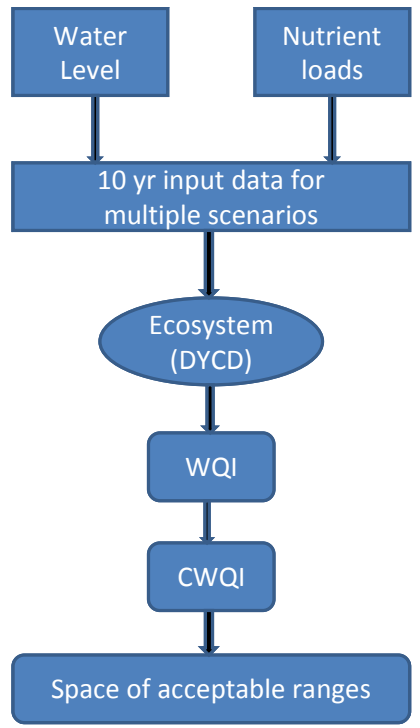

Figure 1: schematic flowchart

\section{RESULTS AND DISCUSSION:}

\subsection{Defining acceptable levels of the management measures:}

For each simulation we calculated the value of the CWQI. The resulting curve describes the changes in the CWQI as a function of multiplication factors, for each loading scenario ( $\mathrm{N}$ load, $\mathrm{P}$ load and N\&P scenarios; figure 2a-c) and WL. The results of the P load scenarios indicated little change in the CWQI values until a multiplication factor of $x 2$ including only limited changes in the values between the various WL. Beyond a factor of $\mathrm{x} 2\left(0.8 \mathrm{gPm}^{-2} \mathrm{y}^{-1}\right)$, CWQI values decreased sharply as the multiplication factor increased. N-load and N\&P load scenarios indicated a different tendency. In the $\mathrm{N}$ load scenarios, we found a tendency of increasing CWQI values from a multiplication factor of $\mathrm{x} 0.1$ to $\mathrm{x} 1$, followed by a decrease beyond a multiplication factor of $\mathrm{x} 1$, for each WL. The maximum CWQI was at a multiplication factor of $\mathrm{x} 1\left(5.66 \mathrm{gNm}^{-2} \mathrm{y}^{-1}\right)$. A similar trend was found in the N\&P load scenarios, where the maximum CWQI was occurred at a N:P ratio of 14.5 (multiplication factor of $\mathrm{x} 1$ ). Since N and N\&P load scenarios exhibited large changes in the CWQI values compared to P load scenarios at the various WL we can conclude that the Lake Kinneret ecosystem is more sensitive to changes in N-load than to P-load.

Since acceptable ranges for the CWQI were restricted to values of 60-100, we found that for Lake Kinneret, WLs below $-214 \mathrm{~m}$ (BSL) corresponded to a CWQI $<60$ regardless of nutrient loading, and were thus unacceptable (figure $2 \mathrm{a}-\mathrm{c}$ ).

For determining the lowest WL in which CWQI $>60$ we increased the resolution between $-213 \mathrm{~m}$ to $214 \mathrm{~m}$ (BSL) and found that CWQI $>60$, could be maintained only when the lake level was above $213.4 \mathrm{~m}$ (BSL). It must be noted that the significance of this find is not in its exact value but in its concept that between $-213 \mathrm{~m}$ and $-214 \mathrm{~m}$ the lower permissible WL could be found. This result is in agreement with the Parparov et al. (2006) study that described the lower permissible lake water level around $-213 \mathrm{~m}$.

We expanded the WL scenarios, from -209.0 to $-213.4 \mathrm{~m}$ (BSL) at a resolution of $0.2 \mathrm{~m}$ and created 23 WLs, using the described approach. We could then assess the direct relationships between nutrient loads and the CWQI for all of the 23 WLs. The graphical solution of these relationships represents a "polygon" of permissible ranges and critical values of nutrient loads allowing conservation of the lake WQ at each WL. Based on these results we sketched 23 different polygons representing each of the simulated lake levels (figure 3). The Relative Solution Domain Area (RSDA) of each polygon represents the permissible ranges of nutrient load and its boundaries represent critical values of nutrient loads allowing conservation of the lake WQ at each WL. By crossing theses boundaries the value of the CWQI decreases below 60 and water quality deteriorates. In other words, each polygon's RSDA represents the acceptable zone of nutrient loads; this RSDA contains all acceptable scenarios for each WL that will allow ecosystem sustainability. It must be mentioned that these polygons represent management boundaries however the realistic boundaries night be different and less concrete. Here we 
wish to present an innovative integrated approach for managing lakes and the exact loading value or WL at which the CWQI falls below the acceptable level is less important.

(a)

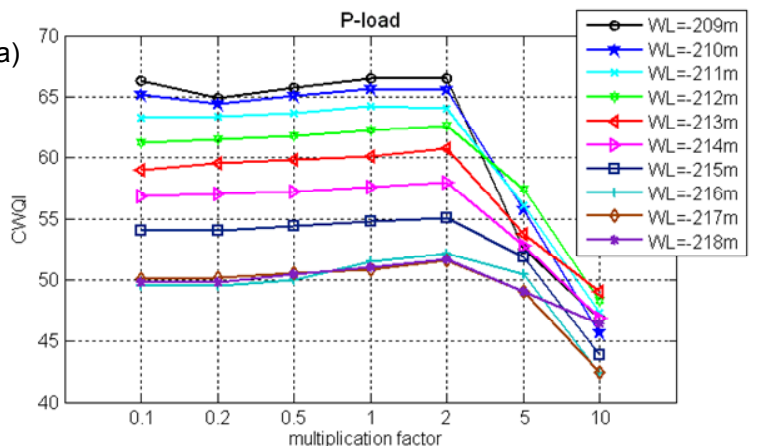

(c)

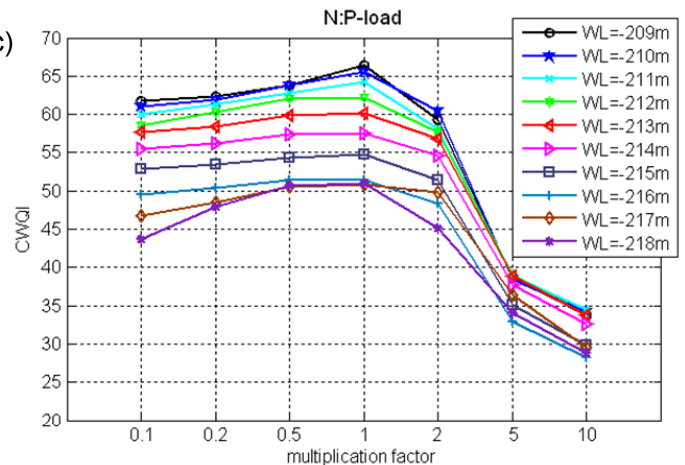

(b)

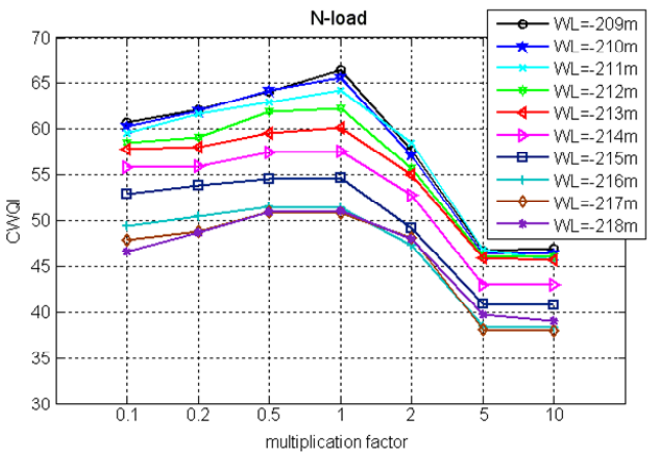

Figure 2: CWQI vs. multiplication factor for different scenarios and for each WL. Note that CWQI values below 60 are deemed unacceptable. (a) P-load scenarios; P-load was varied between 0.039 to $3.9 \mathrm{gPm}^{-2} \mathrm{y}^{-1}$ (multiplication factor $0.1-10$ ) while N-load was kept constant with a value of $5.66 \mathrm{gNm}^{-2} \mathrm{y}^{-}$

${ }^{1}$ (multiplication factor 1). (b) N-load scenarios; N-load was varied between 0.56 to $56.6 \mathrm{gNm}^{-2} \mathrm{y}^{-1}$ while the P-load was kept constant at a value of $0.39 \mathrm{gPm}^{-2} \mathrm{y}^{-1}$. (c) N\&P load scenarios: P-load and Nload was varied simultaneously while the N:P ratio was maintained constant.

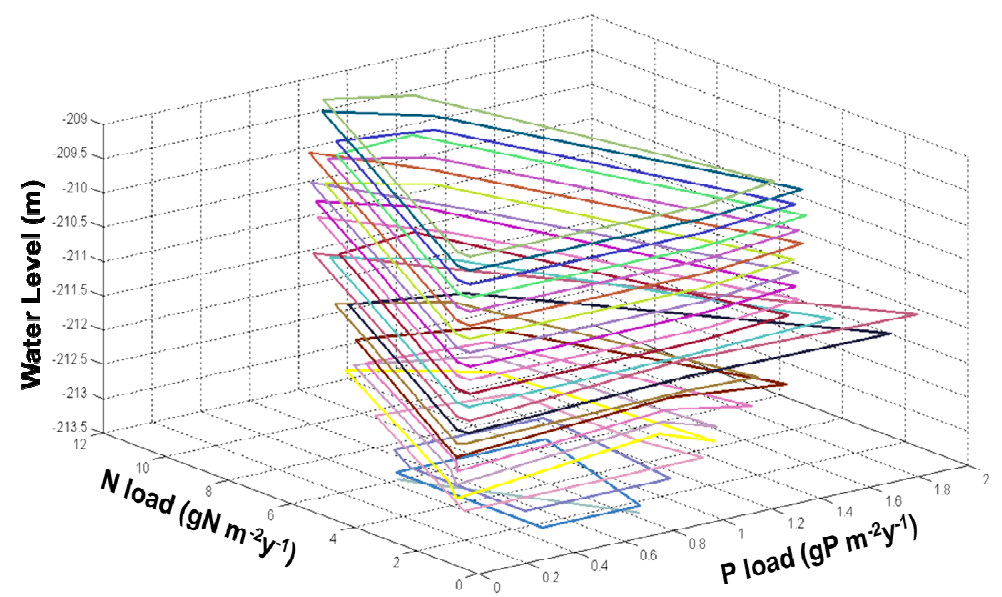

Figure 3: Polygons of permissible ranges of Nload and Pload, allowing maintaining of lake water quality within its permissible range $(60<\mathrm{CWQI}<100)$ at each $\mathrm{WL}$. 
The calculated polygons differ in their Relative Solution Domain Area (RSDA). By calculating the polygons' RSDA we could compare between the permissible ranges of each WL (figure 4). Since the values of the polygons' RSDA were similar for WLs ranging between $-209 \mathrm{~m}$ and $-211.2 \mathrm{~m}$, we defined this range of WLs $(-209 \mathrm{~m}$ to $-211.2 \mathrm{~m})$ as apparently independent of nutrient loads. The calculated polygon RSDA also indicated an unstable optimum at a $\mathrm{WL}=-211.4 \mathrm{~m}$ where the polygon RSDA was the largest. In other words, at a $\mathrm{WL}=-211.4 \mathrm{~m}$ has the largest permissible ranges of nutrient loads. From a lake level of $-211.6 m$ to $213.4 \mathrm{~m}$ the RSDA size decreased with a decrease in water level. At a lake level of

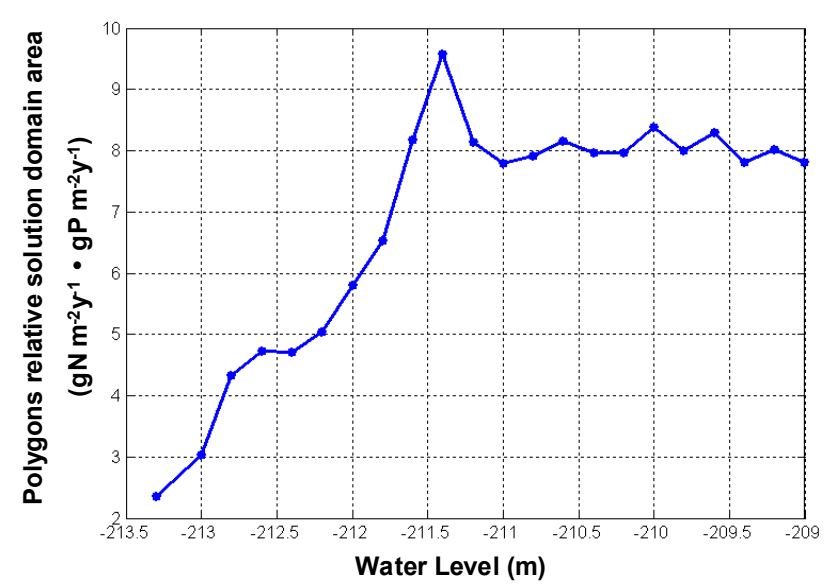

Figure 4: Polygons' area vs. WL. $-213.4 \mathrm{~m}$ the polygon was reduced to a line thus only $\mathrm{N}$ and $\mathrm{P}$ confining to the values of the line will provide a CWQI of at least 60 . All other loading values will lead to a decrease in CWQI and deterioration in water quality. It is important to note that the trend of change in polygon RSDA as function of WL described in figure 4 implies that the reaction of the ecosystem to the management measures is not linear. As a result, reducing management measures, e.g. reducing nutrient loading or pumping from the lake does not always lead to improved conditions.

Integrating all 23 polygons representing the lake level between -209 and $-213.4 \mathrm{~m}$ produced a three dimension (3-D) space which defines all acceptable conditions of $\mathrm{N}$ and $\mathrm{P}$ loads and WLs for Lake Kinneret. This 3-D approach is valuable for research and management. It represents the space of solutions for Lake Kinneret and contains all acceptable combinations of N, P loads and WL that allow conservation of the lake water quality. By using the 3-D space the management policy can be determined. One can set the level of the lake and through the 3-D space find all nutrients loads combinations that maintain $\mathrm{CWQI}>60$ and vice versa, set the nutrient loads entering the lake and find all levels allowing conservation of the lake WQ. This unique approach is the first example known to us in which the management tool integrates both nutrient loads and WL in order to define limits that allow sustainability of the ecosystem. This approach can assist resource managers that need to conform to the European Union requirement from the Union and Associated Members to establish a set of management measures to reach "good" status of the national fresh water bodies by 2015, and to introduce basic principles of sustainable management of water resources (Water Framework Directive, WFD, 2000). This approach can be implemented to other lakes around the world that suffer from deterioration in water quality as a result of changes in water level and nutrients loading or to other combination of types of management measures impacting the ecosystem.

\section{CONCLUSIONS}

In this study we demonstrated a new approach to defining acceptable levels of management measures that will allow sustainable management of water quality in a lake ecosystem. The approach included use of a lake ecosystem model, a quantified system of water quality indices and defined sustainability criteria for the ecosystem. We tested the approach on the Lake Kinneret ecosystem and succeeded in defining the range of acceptable management measures through the use of long term simulations of different scenarios. We created 23 different polygons representing 23 lake levels which denote the permissible ranges of nutrient loads at each WL. By integrating all 23 polygons we created a three dimensional space which defines all acceptable scenarios of $\mathrm{N}$ loads, $\mathrm{P}$ loads and WL thus providing lake managers with an integrated tool for defining the extent of measures that will allow lake ecosystem sustainability. This approach is unique, and the first example of implementation of a management tool that integrates nutrient loads and WL through a WQ system. This approach could be implemented in other lakes around the world that suffer from deterioration in water quality as a result of changes in water level and nutrients loads. 
The application of a process based model, such as DYCD, has provided a means for examining the impact of external forcing on the lake ecosystem, beyond the observed historical conditions, and over extended periods of time. Our study demonstrates the major advantage associated with the use of process based ecosystem models as a tool for research and management.

\section{ACKNOWLEDGMENTS}

Funding was provided by the Israel Water Authority.

\section{REFERENCES}

Berman, T., Stone, L., Yacobi, Y. Z., Kaplan, B., Schlichter, M., Nishri, A., and Pollingher, U. (1995) Primary production and phytoplankton in Lake Kinneret: a long term record (1972-1993). Limnology and Oceanography, 40: 1064-1076.

Berman, T. (1998). Lake Kinneret and its watershed: international pressures and environmental impacts. Water Policy, 1: 193-207.

Bruce, L.C, Hamilton, D., Imberger, J., Gal, G., Gophen, M., Zohary, T. and Hambright, K.D (2006) .A numerical simulation of the role of zooplankton in $\mathrm{C}, \mathrm{N}$ and $\mathrm{P}$ cycling in Lake Kinneret, Israel. Ecological Modelling 193: 412-436.

DeJong, J., van Buuren, J.T. and Luiten, J.P.A. (1996) Systematic approaches in water management: Aquatic outlook and decision support systems combining monitoring, research, policy analysis and information technology. Water Science and Technology, 34: 9-16.

Folke, C., Carpenter, S., Walker, B., Scheffer, M., Elmqvist, T., Gunderson, L., and Holling, C.S. (2004) Regime shifts, resilience, and biodiversity in ecosystem management. Annual Review of Ecology, Evolution, and Systematics, 35:557-81.

Gal, G., Imberger, J., Zohary, T., Antenucci, J.P., Anis, A. and Rosenberg, T. (2003) Simulating the thermal dynamics of Lake Kinneret. Ecological Modelling, 162: 69-86.

Gal, G., Hipsey, M.R., Parparov, A., Wagner, U., Makler, V., Zohary, T. (2009) Implementation of ecological modeling as an effective management and investigation tool: Lake Kinneret as a case study. Ecological Modelling, 220: 1697-1718.

Gal, G., and Williamson, A. (2010) A novel approach to detecting a regime shift in a lake ecosystem. Methods in Ecology and Evolution, 1 (1): 45-52.

Hambright, K.D., Parparov, A. and Berman, T. (2000) Indices of water quality for sustainable management and conservation of an arid region lake, Lake Kinneret (Sea of Galilee ), Israel. Aquatic Conservation, 10: 393-406.

Hipsey, M.R., Romero, J.R., Antenucci J.P. and Hamilton, D (2006) Computational Aquatic Ecosystem Dynamics Model: CAEDYM v2. Science Manual. Contract Research Group, Centre for Water Research University of Western Australia.

Imberger, J., Patterson, J.C. (1981) A dynamic reservoir simulation model-DYRESM: 5. In: Fischer, H.B., (Ed.), Transport Models for Inland and Coastal Waters. Academic Press, New York, pp. 310 361.

Makler-Pick, V., Gal G., Gorfine, M., Hipsey, M. R., Carmel, Y. (2011) Sensitivity analysis for complex ecological models - A new approach. Environmental Modelling \& Software 26: 124-134.

Parparov A. and Gal G., Assessment and implementation of the methodological framework for sustainable management: Lake Kinneret as a case study (submitted)

Parparov A., Hambright. K.D (2007) Composite Water Quality: evaluation and management feedbacks. Water Quality Research Journal of Canada, 42:20-25.

Parparov A., Hambright, K.D., Hakanson. L., and Ostapenia, A. (2006) Water quality quantification: basics and implementation. Hydrobiologia, 560: 227-237.

Priazhinskaya, V.G. (2002) Integrated management of water quality in the Volga River basin. Management in Arid Regions, 3: 235-242.

Serruya C. (1978) Lake Kinneret. Dr. W. Junk, The Hague, 501 p.

Wang, X. (2001) Integrating water-quality management and land-use planning in a watershed context. Journal of environmental management 61: 25-36.

Zohary, T. (2004) Changes to the phytoplankton assemblage of Lake Kinneret after decades of a predictable, repetitive pattern. Freshwater Biology, 49: 1355-1371.

Zohary, T., and Ostrovsky, I. (2011) Ecological impacts of excessive water level fluctuations in stratified freshwater lakes. Inland Waters, 1:47-59. 